\title{
The Yellow Fever 17D Vaccine Virus as a Vector for the Expression of Foreign Proteins: Development of New Live Flavivirus Vaccines
}

\author{
Myrna C Bonaldo, Philippe S Caufour, Marcos S Freire*, Ricardo Galler/ ${ }^{+}$
}

Departamento de Bioquímica e Biologia Molecular, Instituto Oswaldo Cruz *Departamento de Desenvolvimento Tecnológico, Instituto de Tecnologia em Imunobiológicos-Fiocruz, Av. Brasil 4365, 21045-900

Rio de Janeiro, RJ, Brasil

The Flaviviridae is a family of about 70 mostly arthropod-borne viruses many of which are major public health problems with members being present in most continents. Among the most important are yellow fever $(Y F)$, dengue with its four serotypes and Japanese encephalitis virus. A live attenuated virus is used as a cost effective, safe and efficacious vaccine against YF but no other live flavivirus vaccines have been licensed. The rise of recombinant DNA technology and its application to study flavivirus genome structure and expression has opened new possibilities for flavivirus vaccine development. One new approach is the use of cDNAs encopassing the whole viral genome to generate infectious RNA after in vitro transcription. This methodology allows the genetic mapping of specific viral functions and the design of viral mutants with considerable potential as new live attenuated viruses. The use of infectious cDNA as a carrier for heterologous antigens is gaining importance as chimeric viruses are shown to be viable, immunogenic and less virulent as compared to the parental viruses. The use of DNA to overcome mutation rates intrinsic of RNA virus populations in conjunction with vaccine production in cell culture should improve the reliability and lower the cost for production of live attenuated vaccines. The YF virus despite a long period ignored by researchers probably due to the effectiveness of the vaccine has made a come back, both in nature as human populations grow and reach endemic areas as well as in the laboratory being a suitable model to understand the biology of flaviviruses in general and providing new alternatives for vaccine development through the use of the $17 D$ vaccine strain.

Key words: yellow fever virus - 17D vaccine - foreign gene expression - recombinant viruses vaccine development

The Flavivirus genus consists of about 70 viruses mostly arthropod-borne, being transmitted to vertebrates by mosquitoes or ticks. These viruses can be divided into eight serological subgroups based on cross neutralization tests and members of these groups exist in most continents being responsible for significant human disease in these areas. The most important flaviviruses are yellow fever (YF) in the Americas and Africa (Monath 1999) dengue (DEN) virus with its four serotypes and its spreading throughout the tropics with increasing frequency of the more severe forms of this disease (dengue hemorrhagic fever and dengue shock syndrome, Halstead 1988) as well as Japanese encephalitis (JE) with its epidemic and endemic profile in Asia (Monath 1988). Control

${ }^{+}$Corresponding author. Fax: +55-21-590.3495

E-mail: rgaller@gene.dbbm.fiocruz.br

Received 7 August 2000

Accepted 4 September 2000 of flavivirus transmission has been accomplished mainly by vector control measures and vaccination. Approved vaccines are available only for YF using the attenuated live 17D virus (Theiler \& Smith 1937a,b), tick-borne encephalitis (TBE) and JE both as inactivated virus. For DEN and JE viruses candidate vaccines have been developed using serial passages in cultured vertebrate cells and tested in humans (Bhamarapravati \& Yoksan 2000) but so far none has been licensed.

\section{YF VACCINE DEVELOPMENT}

In 1927 the Asibi strain (Stokes et al. 1928) of wild YF virus was isolated from a young African named Asibi by passage in Rhesus monkey (Macaca mulatta). In 1935 the Asibi strain was adapted to growth in mouse embryonic tissue (Lloyd et al. 1936). After 17 passages the virus, named 17D, was further cultivated until passage 58 in whole chicken embryonic tissue and thereafter until passage 114 in denervated chicken embryonic tissue only. At this stage Theiler and Smith (1937a) showed the marked reduction in viral 
viscero and neurotropism when inoculated intracerebrally in monkeys. This virus was further subcultured until passages 227 and 229 and these vaccines without human immune serum were used to immunize eight human volunteers (Theiler \& Smith 1937b). With satisfactory results, as shown by the absence of adverse reactions and seroconversion for YF in two weeks, larger scale immunization was carried out in Brazil (Smith et al. 1938).

The YF 17D virus is one of the most successful vaccines developed to date. It has a well-defined and efficient production methodology, there is strict quality control including monkey neurovirulence testing, it induces long lasting immunity, it is cheap and single dose. Its use has been estimated use to be over 200 million doses with an excellent record of safety. Here, only 21 cases of post-vaccinal encephalitis have been recorded after seed lot system implementation in 1945 with incidence on very young infants $(<9$ months; rate of $0.5-4 / 1000$ and $\geq 9$ months, $1 / 8$ million; WHO 1993, Monath 1999).

With such characteristics it was appealing to attempt to use of 17D as vector for the expression of heterologous antigens what might lead to the development of new live vaccines.

\section{YELLOW FEVER VIRUS GENOME STRUCTURE AND EXPRESSION}

The flaviviruses are spherical viruses with 40$60 \mathrm{~nm}$ in diameter with an icosahedral capsid which contains a single positive-stranded RNA molecule. Its replication is entirely cytoplasmic and budding in general occurs into the lumen of the rough endoplasmic reticulum cisternae. With the development of recombinant DNA technology, novel approaches to understanding RNA virus genome structure and expression were possible. For flaviviruses the first studies appeared in the mid 80 's and included the complete genome sequences of YF 17D (Rice et al. 1985) and West Nile viruses (WN; Wengler et al. 1985). Nucleotide and protein sequence data were subsequently obtained by several laboratories and are the basis for our current knowledge of genome structure and expression.

The YF virus RNA genome consists of 10,862 nucleotides in length with short 5' (118 nucleotides) and 3' (511 nucleotides) untranslated regions, a 5' cap structure and a nonpolyadenylated 3 ' end. Conserved RNA sequences and secondary structures which may be important for flavivirus replication and/or packaging have been identified (Chambers et al. 1990a). This single RNA is also the viral message and its translation in the infected cell results in the synthesis of a polyprotein precursor which undergoes postranslational, but pos- sibly also cotranslational, proteolytic processing to generate ten virus-specific polypeptides. From the 5 ' terminus the order of the encoded proteins is the following: C-prM/M; E, NS1, NS2A, NS2B, NS3, NS4A, NS4B, NS5 (Rice et al, 1985; see Fig. 1).

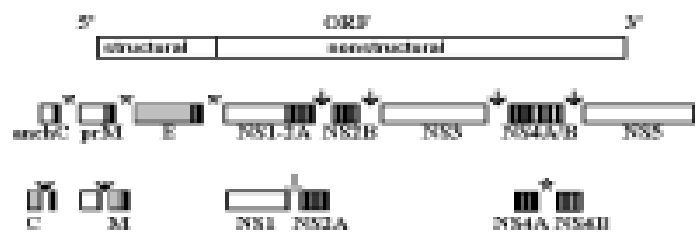

Fig. 1: schematic of the flavivirus genome structure expression. The top represents the whole flavivirus genome with the structural and nonstructural protein coding regions. The boxes below the genome represent precursors and the mature viral proteins generated by proteolytic processing. Shaded boxes represent the structural proteins and open boxes the nonstructural proteins. Black bars represent the stretches of hydrophobic amino acids and asterisks the $\mathrm{N}$-linked glycosylation sites. Asterisks represent cleavage by cellular signalase; solid arrows, cleavage by the viral NS2B-NS3 complex, including the cleavage of the anchored form of the capsid protein; the open arrow at the NS1/2A cleavage is a novel still unknown proteolytic activity.

The first three proteins constitute the structural proteins, that is, form the virus together with the packaged RNA molecule and were named capsid (C, $12-14 \mathrm{kDa})$, membrane $(\mathrm{M}$, and its precursor prM, 18-22 kDa) and envelope (E,52-54 kDa) all being encoded in the first quarter of the genome. The remainder of the genome codes for the nostructural proteins (NS) numbered in the order of synthesis from 1 through 5. Three large nonstructural proteins have highly conserved sequences among flaviviruses, NS1 (38-41 kDa), NS3 (68-70 kDa) and NS5 (100-103 kDa). A role in the replication of the negative strand RNA has been assigned to NS1 (Muylaert et al. 1996, 1997, Lindenbach \& Rice 1997, 1999). NS3 has been shown to be bifunctional with a protease activity needed for the processing of the polyprotein at sites where the cellular proteases will not (Chambers et al. 1990b, Falgout et al. 1991, Yamshikov \& Compans 1995, Yamshchikov et al. 1997, Stocks \& Lobigs 1998) and nucleotide triphosphatase/ helicase activities (Gorbalenya et al. 1989, Wengler \& Wengler 1993) being therefore also associated with viral RNA replication. NS5, the largest and most conserved viral protein, contains several sequence motifs believed to be common to viral RNA polymerases (Chambers et al. 1990a, O’Reilly \& Kao 1998) and exhibits RNA-dependent RNA polymerase activity (Steffens et al. 1999). A number of cis and trans acting elements in flavivirus 
RNA replication have been identified (Kromykh et al. 2000).

The four small proteins NS2A, NS2B, NS4A and NS4B are poorly conserved in their amino acid sequences but not in their pattern of multiple hydrophobic stretches. NS2A has been shown to be required for proper processing of NS1 (Falgout et al. 1989) whereas NS2B has been shown to associate with NS3 to constitute the active viral protease complex (Falgout et al. 1991, Chambers et al. 1993, Jan et al. 1995). NS4A has been suggested to interact with NS1 integrating it into the cytoplasmic process of RNA replication (Lindenbach \& Rice 1999). Since viral RNA synthesis takes place in the cytosol in association with RER membranes it has been postulated that these hydrophobic proteins would be embebded in membranes and through protein-protein interactions participate in viral replication complexes together with NS3 and NS5 (Rice 1996).

Among the possibilities to apply molecular techniques to the development of new vaccines our capability of recovering virus from cloned DNA in which genetic modifications are made is of utmost importance and described below.

\section{INFECTIOUS CLONE TECHNOLOGY}

In order to manipulate RNA genomes, complementary DNAs corresponding to the complete genome must be available to allow introducing genetic modifications at any particular site of the viral genome. The pioneer study of Racaniello and Baltimore (1981) first showed the feasibility to generate poliovirus from cloned cDNA. With the development of in vitro transcription systems it became possible to synthesize in vitro full length viral RNA with a much higher efficiency as compared to cDNA transcription in the cell. The development of more efficient transfection methodologies such as cationic liposomes and electroporation improved the efficiency of RNA transfection of cultured cells. The basic methodology for what is known today as infectious clone technology was set. For a number of positive stranded viruses, infectious cDNA has been obtained and can be used to understand the molecular basis of several biological phenomena such as: virulence/ attenuation, cell penetration, replication, host range, conditional mutants and the design of mutants in genome regions for which no function is known. Conceivably development of new live vaccine viruses could or should include mutations in different areas as to render reversion less likely and affect one or more of the traits above. The Table shows a list of infectious clones presently available and some of the studies which have been carried out using this technology.
THE USE OF YF 17D VIRUS FOR THE EXPRESSION OF HETEROLOGOUS FLAVIVIRUS PROTEINS

Characteristics of YF17D viruses recovered from $c D N A$ - The first aspect that has to be considered when using a given flavivirus cDNA backbone for the expression of heterologous proteins is whether one can indeed recover virus with the same phenotypic markers as originally present in the virus population that gave rise to the cDNA library. For YF 17D these analyses would be important to set the precedent for infectious clones derived vaccines given the well known safety and efficacy of YF 17D vaccine. It would also be important to show that indeed attenuated virus can be recovered from the cDNA which is to be used as a vector for heterologous antigens such as dengue. However, the virus recovered from the first version of the infectious clone based on 17D-204 virus (see Fig. 2) gave rise to virus with a slightly higher clinical score in a monkey neurovirulence test (Marchevsky et al. 1995). Although these results showed the virus was not ideally attenuated for YF 17D vaccine it was the first demonstration for a flavivirus that it was possible to develop from a few micrograms of DNA template a whole seed lot under good manufacturing practices (GMP) using current methodology for the production of YF vaccine.

Galler et al. (unpublished) have approached the recovery of fully attenuated virus from YF cDNA by engineering a number of mutations into the original 17D-204 cDNA (Rice et al. 1989) based on the sequence of the 17DD substrain (Duarte dos Santos et al. 1995). This substrain has been used in Brazil for YF vaccine production since the late 30's with excellent records of efficacy and safety. Here, virus was recovered from the geneticallymodified cDNA template through the transfection of certified CEF cells under GMP. Altogether three transfection lots were derived which gave rise to two primary and three secondary seed lots all in by further passaging in CEF cells with all the relevant quality controls as established for measles vaccine production using this cell system. Average titer of formulated virus was $6.7 \log _{10} \mathrm{PFU} /$ $\mathrm{ml}$. Further analysis of viral genetic stability was carried out by: serial passaging in CEF cultures and studying several parameters such as plaque size, mouse neurovirulence and nucleotide sequence determination with satisfactory results. The final phenotypic analysis that requires the internationally accepted monkey neurovirulence testing is ongoing.

It follows below the presentation of some progress towards the development of new live flavivirus vaccines using YF 17D virus. The examples include the creation of chimeric viruses 
TABLE

Flavivirus infectious clones and applications

\section{YELLOW FEVER}

E: changes in domains I, II, III. Vaccine (Galler et al. unpublished) and Asibi-related (C Rice, pers. commun.) NS1: N-linked glycosylation mutants, charged-to-alanine mutants (Muylaert et al. 1996, 1997)

NS2A/2B: mutagenesis of cleavage site (Nestorowicz et al. 1994)

NS2B: changes in variable hydrophobic and conserved hydrophilic domains (Chambers et al. 1993)

NS3: mutagenesis at the catalytic triad of protease domain (Chambers et al. 1990b).

NS4A/4B: mutagenesis at the signalase cleavage site (Lin et al. 1994)

NS5: vaccine (Galler et al. unpublished) and Asibi-related (C. Rice, pers. commun.)

Construction of chimeric viruses: JE (Chambers et al. 1999, Guirakhoo et al. 1999, 2000, Monath et al. 1999, 2000). DEN-2 (Lindenbach \& Rice 1999, Galler et al. in preparation)

\section{DENGUE TYPE 2}

Strains: New Guinea C (Kapoor et al. 1995), PDK53/16881 (Kinney et al. 1997), NGC/PUO218 (Gualano et al. 1998)

E: reversion to virulence in mice (Gualano et al. 1998, Bray et al. 1998)

NS1: protein secretion and dimer formation (Pryor et al. 1998)

NS3: temperature-sensitive mutant (Kinney et al. 1997)

Construction of chimeric viruses: DEN-2/1 (Huang et al. 2000)

Mapping attenuation determinants (Butrapet et al. 2000)

\section{DENGUE TYPE 4}

E: virulence for mice (Bray et al. 1992)

NS1: N-linked glycosylation mutants (Pletnev et al. 1993)

5 ' end: changes in conserved sequence (Cahour et al. 1995)

3' end: deletions (Men et al. 1996)

Construction of chimeric viruses: Den1-2-3, TBE, Langat (Lai et al. 1998)

\section{JAPANESE ENCEPHALITIS}

E: virulence in mice (Sumiyoshi et al. 1992)

\section{OTHER FLAVIVIRUS INFECTIOUS CLONES}

Den 1 cloned in yeast (Pur et al. 2000)

Kunjin (Kromykh \& Westaway 1994)

TBE (Mandl et al. 1998)

through the exchange of prM/M/E genes (Fig. 3) as first established for DEN-4 virus chimeras (Lai et al. 1998). This allows the removal of the major immunogens of the vector thereby reducing the criticism on previous immunity to the vector. It remains to be carefully established whether immunity to NS1 and NS3 proteins may hamper replication of the virus and reduce its immunogenicity.

Construction of chimeric flaviviruses - The construction of chimeric viruses as an alternative to developing new vaccines based on the mapping of virulence determinants has become a reality. The rationale behind this approach is to have cDNA from a virus with well known vaccine properties and to use this cDNA as a carrier for heterologous antigens, once the virus recovered from it is also shown to be attenuated. The feasibility of this approach was first demonstrated for poliovirus (reviewed in Rose \& Evans 1990). The development of infectious cDNA for dengue virus type 4 (Lai et al. 1991) allowed the construction of new chimeric dengue viruses (Bray \& Lai 1991, Lai et al. 1998, see Fig. 3). The prM/M/E genes of dengue virus serotypes 1, 2 and 3 were inserted into the dengue 4 infectious clone resulting in chimeric virus with reduced virulence for mice and monkeys (Lai et al. 1998). The same type of construction was made for TBE and Langat viruses (Pletnev et al. 1992, 1993, Pletnev \& Men 1998) resulting in virus attenuated for mice. The main pitfall with the development of such chimeras with dengue type 4 virus infectious cDNA is the fact that the DEN-4 backbone derives from a wild type virus. On the other hand, having the YF 17D virus generated from infectious cDNA produced according to GMP using current methodology for YF and having shown its attenuation, it would be worth trying to construct chimeric viruses having the 17D 
backbone and $\mathrm{prM} / \mathrm{M} / \mathrm{E}$ genes of DEN viruses fused in frame to it as to make up the complete flavivirus genome and hopefully functional. The production and testing of such chimeric viruses could be carried out as determined for YF virus.

Development of YF 17D/JE chimeric viruses Chambers et al. (1999) have described the first chimeric virus developed with the YF 17D cDNA

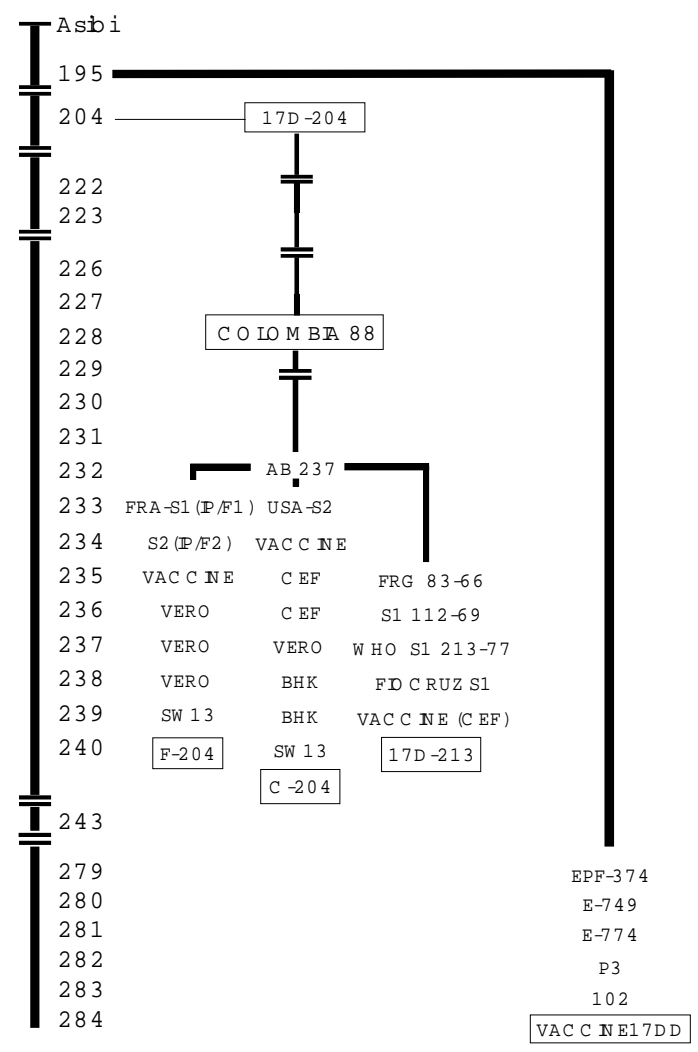

Fig. 2: passage history of the original yellow fever (YF) Asibi strain and derivation of YF 17D vaccine strain and its substrains. The YF virus Asibi strain was subcultured in embryonic mouse tissue and minced whole chicken embryo with or without nervous tissue. These passages yielded the parent 17D strain at passage level 180, 17DD at passage 195, and the 17D-204 at passage 204. 17DD was further subcultured until passage 243 and underwent 43 additional passages in embryonated chicken eggs until the passage 284 which is currently the passage for vaccine batches in use for human vaccination. The 17D-204 was further subcultured to produce Colombia 88 strain which, upon passage in embryonated chicken eggs, gave rise to vaccine seed lots currently in use in France (I Pasteur, at passage 235) and in the USA (Connaught, at passage 234). The 17D-213 strain was derived from 17D-204 when the primary seed lot (S1 112-69) from the Federal Republic of Germany (FRG 83-66) was used by the World Health Organization (WHO) to produce an avian leukosis virus-free 17D seed ( $S 1$ 213/77) at passage 237. This 213/77 seed was used to prepare a primary seed at the Oswaldo Cruz Foundation (Fiocruz S1) which was passed once more in cultured chicken embryo fibroblasts to produce experimental vaccine batches at passage 239 . from Rice et al. (1989) by the exchange of the prM/ $\mathrm{M} / \mathrm{E}$ genes with cDNA derived from JE SA14-142 and Nakayama strains of JE virus. The former corresponds to the live attenuated vaccine strain in use nowadays in China.

Guirakhoo et al. (1999) and Monath et al. (1999, 2000) have brought it closer to vaccine development. Here, chimeric virus was recovered after transfection of certified FRhL cells with five additional passages of the virus to produce seed lots and experimental vaccine lot (5th passage) all under GMP in certified cells. Virus yields in this cell system were not provided.

Chimeric virus retained nucleotide/amino acid sequences present in the original SA14-14-2 strain. This vaccine strain differs, in $\mathrm{prM} / \mathrm{M} / \mathrm{E}$ region, from the parental virus in six positions (E-107; E138; E176: E279; E315; E439). Mutations are stable across multiple passages in cell culture (Vero) and mouse brain but not in FRhL cells. Despite previous data on the genetic stability of such virus, one of the four changes in the E protein related to viral attenuation had reverted, during the passaging to produce the secondary seed.

Initial phenotypic characterization of FRhL 5th passage virus by inoculation in mice suggested it is not neurovirulent in contrast to the $17 \mathrm{D}$ vaccine virus. Monkey neurovirulence test with YF 17D virus and 17D/JE-FRhL-3rd passage resulted in low viremia for both viruses and lower clinical and histopathological scores for the chimeric virus as compared to $17 \mathrm{D}$.

In a dose-response study neutralizing antibodies specific for $\mathrm{prM} / \mathrm{M} / \mathrm{E}$ were elicited in all groups of monkeys with different doses even with as little as 100 PFUs and conferred full protection against IC challenge with wild type JE. However, the lower the chimeric virus dose the more residual histopathological changes were noted in the SNC after IC challenge with wild type JE virus. Thirteen/ sixteen monkeys developed significant increase in $\mathrm{N}$ antibodies after challenge suggesting viral replication and booster immune response. It was concluded that Chimerivax 17D/JE SA14-14-2 virus meets preclinical safety and efficacy requirements for a human vaccine, it appears safer than 17D virus but has a similar profile of immunogenicity and protective efficacy.

Development of chimeric 17D/dengue viruses - The first chimeric 17D/dengue virus developed (Guirakhoo et al. 2000) involved prM/M/E gene replacement (fusion at the signalase cleavage site, Fig. 3) with a den 2 cDNA from PUO218 strain (wild type virus from a DF case, Thailand 1980). All virus regeneration and passaging was done in Vero PM cells (a cell bank from Pasteur-Merieux) allegedly certified for live vaccine virus produc- 
a)

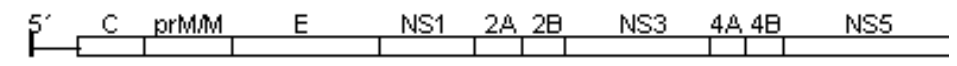

b)

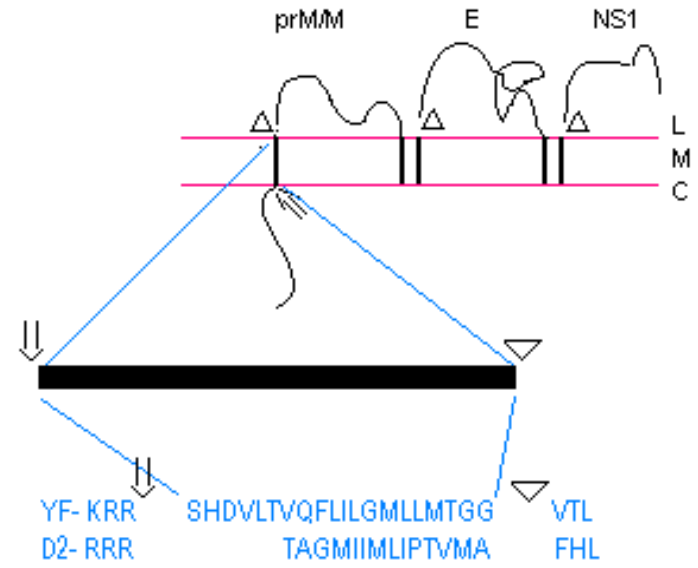

e)
C $\mathrm{prM} / \mathrm{M}$
$\mathrm{E}$
NS1 2A $2 \mathrm{~B}$
NS3
$4 \mathrm{~A}$
4B

Fig. 3: schematic representation of proteolytic cleavages at the flavivirus polyprotein C-prM region. In (a) the flavivirus genome structure is depicted. In (b) is shown the proposed spatial arrangement of the translational complex at the C-NS1 region into the ER lipidic membrane. The solid vertical black bars represent hydrophobic transmembrane domains. In (c) the transmembrane domain between $\mathrm{C}$ and $\mathrm{prM}$ is represented and flanked on the left by the viral protease NS2B-3 cleavage that takes place in the cytoplasm, and on the right by the signalase cleavage which occurs in the ER lumen. In (d) is shown the amino acid sequence present in this hydrophobic transmembrane domain for both YF and den2 viruses and (e) represents the genome structure of a chimeric virus with a prM/M/E gene replacement with precise fusion at the signalase cleavage sites in C-prM and E/NS1.

tion. Recombinant virus retained PUO218 prM/ $\mathrm{M} / \mathrm{E}$ sequences even after 18 serial passages in Vero cells but some variation was noted in YF genes. Phenotypic analysis of chimeric 17D/den2 virus showed it does not kill mice even at high doses (6 $\log _{10}$ PFU) in contrast to YF 17D which kills nearly $100 \%$ at $3 \log _{10} \mathrm{PFU}$. Antibody response and full protection were elicited by the 17D-DEN2 chimera in both YF immune and flavivirus-naive monkeys. In a dose response study even at the lowest dose $\left(2 \log _{10} \mathrm{PFU}\right)$ chimeric virus replicated sufficiently to induce a protective neutralizing antibody response as no viremia was detected in these animals after challenge with a wild type dengue 2 virus.

Galler et al. (in preparation) have also developed a similar chimeric 17D-DEN-2 virus. However, the 17D backbone used was different since it was the modified version of it (Galler et al. in preparation, see above). In addition to using the DEN-2 $\mathrm{prM} / / \mathrm{M} / \mathrm{E}$ genes of the DEN-2 PUO218 strain they have also derived a second chimeric virus containing the carboxi terminal third of $E$ from a Brazilian strain of DEN-2 virus. These viruses were char- acterized at the genomic level by RT/PCR with YF/ Den-specific primers and nucleotide sequencing over fusion areas and the whole DEN2-moieties. The polyprotein expression/processing was monitored by SDS-PAGE analysis of radiolabeled viral proteins immunoprecipitated with specific antisera, including monoclonal antibodies. Recognition of YF and DEN-2 proteins by hiperimmune antisera, and monoclonal antibodies was also accomplished by viral neutralization in plaque formation reduction tests and indirect immunofluorescence on infected cells. The growth of recombinant viruses was examined in several cell substrates such as Vero, LLC-MK 2 , C6/36, MRC5, and CEF. Only YF virus grew in all of them to high titers but the chimeric viruses failed to replicate in the vaccine-production certified cells (CEF and MRC5) similarly to DEN-2 virus. Therefore, it remains to be seen whether any other certified cell can be used for virus production and whether Vero cells will become an acceptable substrate for this purpose. Analysis of viral virulence was performed by intracerebral inoculation of mice $\left(10^{3}\right.$ PFU) and the viruses turned out to be more attenu- 
ated in this system than the YF 17D virus. With regard to the immunogenicity, although no monkey studies were performed, as described by Guirakhoo et al. (2000), studies in the mouse model indicate the chimeric virus does induce a protective response against an otherwise lethal dose of mouse neurovirulent DEN-2 New Guinea $C$ virus.

\section{CONCLUSIONS/PERSPECTIVES}

YF 17D virus has several characteristics which are desirable for vaccines in general and that has attracted the interest of several laboratories in developing it further to be used as a vector for heterologous antigens. The application of molecular techniques to the study of flavivirus genome structure and expression led to new approaches to understand viral biology. The development of infectious clone technology has allowed the genetic manipulation of YF 17D genome towards the expression of foreign genes. It has been shown that the preparation of clinical grade viral seed lots suitable for vaccine production from cDNA is feasible and that was a first step forward to scale up such development. In this regard, infectious clone technology allowed the construction of new chimeric live flaviviruses which appear attenuated and immunogenic in experimental animal models and should in a short term undergo clinical testing.

Infectious clone technology has already unreveled some mechanisms which may lead to viruses altered at specific points of the viral cycle. Attenuation can be effected by introducing multiple changes and making the mutant less prone to reversion given the high mutation rate of RNA viruses. These mutants could be used for experimental infections if the appropriate animal models are available and may result in viruses with potential as new live vaccine. Infectious clone technology has a huge potential to generate new viruses. It is likely that by the time we realize that chimeric viruses may not be the ideal vaccine enough data will have accumulated on several viral functions that will allow the rational development of viruses bearing multiple mutations. This is turning into a major trend in flavivirus research.

\section{REFERENCES}

Bhamarapravati N, Yoksan S 2000. Live attenuated tetravalent dengue vaccine. Vaccine 18: 44-47.

Bray M, Lai CJ 1991. Construction of intertypic chimeric dengue viruses by substitution of structural protein genes. Proc Natl Acad Sci USA 88:10342-10346.

Bray M, Men R, Tokimatsu I, Lai CJ 1998. Genetic determinants responsible for acquisition of dengue type 2 virus mouse neurovirulence. J Virol 72: 16471651.

Butrapet S, Huang CYH, Pierro DJ, Bhamarapravati N, Gubler DJ, Kinney RM 2000. Attenuation markers of a candidate dengue type 2 vaccine virus, strain 16681 (PDK-53), are defined by mutations in the 5 'noncoding region and nonstructural proteins 1 and 3. J Virol 74: 3011-3019.

Cahour A, Pletnev A, Vazeille-Falcoz M, Rosen L, Lai CJ 1995. Growth-restricted dengue virus mutants containing deletions in the 5'noncoding region of the RNA genome. Virology 207: 68-76.

Chambers TJ, Hahn CS, Galler R, Rice CM 1990a. Flavivirus genome organization, expression and evolution. Ann Rev Microbiol 44: 649-688.

Chambers TJ, Nestorowicz A, Amberg SM, Rice CM 1993. Mutagenesis of the yellow fever virus nonstructural polyportein: a catalitically active NS3 proteinase domain and NS2B are required for cleavages at dibasic sites. $J$ Virol 65: 6797-6807.

Chambers TJ, Nestorowicz A, Mason PW, Rice CM 1999. Yellow fever/Japanese encefalitis chimeric viruses: construction and biological properties. $J$ Virol 73: 3095-3101.

Chambers TJ, Weir RC, Grakoui A, McCourt DW, Bazan JF, Fletterick RJ, Rice CM 1990b. Evidence that the $\mathrm{N}$-terminal domain of nonstructural protein NS3 from yellow fever virus is a serine protease responsible for site-specific cleavages in the viral polyprotein. Proc Natl Acad Sci USA 87: 8898-8902.

Duarte dos Santos CN, Post PR, Carvalho R, Rice CM, Galler R 1995. Complete nucleotide sequence of the genome from yellow fever virus 17DD and 17D213 vaccine strains. Virus Research 35: 35-41.

Falgout B, Channock R, Lai CJ 1989. Proper processing of dengue virus nonstructural glycoprotein NS1 requires the $\mathrm{N}$-terminal hydrophobic signal sequence and the downstream nonstructural protein NS2A. $J$ Virol 63:1852-1860.

Falgout B, Pethel M, Zhang YM, Lai CJ 1991. Both nonstructural proteins NS2B and NS3 are required for the proteolytic processing of dengue virus nonstructural proteins. J Virol 65: 2467-2475.

Gorbalenya AE, Koonin EV, Donchenko AP, Blinov VM 1989. Two related superfamilies of putative helicases involved in replication, recombination repair and expression of DNA and RNA genomes. Nucl Acids Res 17: 4713-4730.

Gualano RC, Pryor MJ, Cauchi MR, Wright PJ, Davidson AD 1998. Identification of a major determinant of mouse neurovirulence of dengue virus type 2 using stably cloned genomic-length cDNA. J Gen Virol 79: 437-446.

Guirakhoo F, Zhang ZX, Chambers TJ, Delagrave S, Arroyo J, Barrett ADT, Monath TP 1999. Immunogenicity, genetic stability and protective efficacy of a recombinant, chimeric yellow fever -Japanese encephalitis virus (Chimerivax-JE) as a live, attenuated vaccine candidate against fever Japanese encephalitis. Virology 257: 363-372.

Guirakhoo F, Weltzin R, Chambers TJ, Zhang ZX, Soike K, Rattterree M, Arroyo J, Georgakopoulos K, Catalan J, Monath TP 2000. Recombinant chimeric yellow fever-Dengue type 2 virus is immunogenic and protective in nonhuman primates. J Virol 74: 5477-5485. 
Halstead SB 1988 Pathogenesis of dengue: challenges to molecular biology. Science 239: 476-481.

Huang CYH, Butrapet S, Pierro DJ, Chang GJJ, Hunt AR, Bhamarapravati N, Gubler DJ, Kinney RM 2000. Chimeric dengue type 2 (vaccine strain PDK53 )/dengue type 1 virus as potential candidate dengue type 1 virus vaccine. J Virol 74: 3020-3028.

Jan LR, Yang CS, Trent DW, Falgout B, Lai CJ 1995. Processing of Japanese encephalitis virus non-structural proteins:NS2B-NS3 complex and heterologous proteases. J Gen Virol 76: 573-580.

Kapoor M, Zhang L, Mohan PM, Padmanabhan R 1995. Synthesis and characterization of an infectious dengue virus type 2 RNA genome (New Guinea C strain). Gene 162: 175-180.

Kinney RM, Butrapet S, Chang GJJ, Tsuchiya R, Roehrig JT, Bhamarapravati N, Gubler DJ 1997. Construction of infectious cDNA clones for dengue 2 virus: strain 16681 and its attenuated vaccine derivative strain PDK-53. Virology 230: 300-308.

Kromykh AA, Westaway EG 1994. Completion of Kunjin virus RNA sequence and recovery of an infectious RNA transcribed from stably cloned fulllength cDNA. $J$ Virol 68: 4580-4588.

Kromykh AA, Sedlak PL, Westaway EG 2000. cis- and trans-acting elements in flavivirus RNA replication. J Virol 74: 3253-3263.

Lai CJ, Bray M, Men R, Cahour A, Chen W, Kawano H, Tadano M, Hiramatsu K, Tokimatsu I, Pletnev A, Arakai S, Shameen G, Rinaudo M 1998. Evaluation of molecular strategies to develop a live dengue vaccine.Clin Diagn Virol 10: 173-179.

Lai CJ, Zhao BT, Hory H, Bray M 1991. Infectious RNA transcribed from stably cloned full-length cDNA of dengue type 4 virus. Proc Natl Acad Sci USA 88: 5139-5143.

Lin C, Amberg SM, Chambers TJ, Rice CM 1994. Cleavage at a novel site in the NS4A region by yellow fever virus NS2B-3 proteinase is a prerequisite for processing at the downstream $4 \mathrm{~A} / 4 \mathrm{~B}$ signalase site. J Virol 67: 2327- 2335.

Lindenbach BD, Rice CM 1997. Trans-complementation of yellow fever virus NS1 reveals a role in early RNA replication. J Virol 71: 9608-9617.

Lindenbach BD, Rice CM 1999. Genetic interaction of flavivirus nonstructural proteins NS1 and NS4A as a determinant of replicase function. $J$ Virol 73: 46114621.

Lloyd W, Theiler M, Ricci NI 1936. Modification of the virulence of yellow fever virus by cultivation in tissues. Trans R Soc Trop Med Hyg 29: 481-529.

Mandl CW, Holzmann H, Meisner T, Rauscher S, Stadler PF, Allison SL, Heinz FX 1998. Spontaneous and engineered deletions in the $3^{\prime}$ noncoding region of tick-borne encephalitis virus: construction of highly attenuated mutants of a flavivirus. $J$ Virol 72: 21322140.

Marchevsky RS, Mariano J, Ferreira VS, Cerqueira MJ, Almeida E, Carvalho R, Travassos da Rosa APA, Simões MC, Santos CND, Ferreira II, Muylaert IR, Rice CM, Galler R 1995. Phenotypic analysis of yelow fever virus derived from cloned complemen- tary DNA. Am J Trop Med Hyg 52: 75-80.

Men R, Bray M, Clark D, Chanock RM, Lai CJ 1996. Dengue type 4 virus mutants containing deletions in the 3'noncoding region of the RNA genome: analysis of growth restriction in cell culture and altered viremia pattern and immunogenicity in rhesus monkeys. J Virol 70: 3930-3937.

Monath TP 1988 Japanese encephalitis: a plague of the Orient. N Engl J Med 319: 641-645.

Monath TP 1999 Yellow Fever. In S Plotkin, W Orenstein (eds), Vaccines, WB Saunders, USA, p. 815-998.

Monath TP, Levenbook I, Soike K, Zhang ZX, Rattterree M, Draper K, Barrett ADT, Nichols R, Weltzin R, Arroyo J, Guirakhoo F 2000. Chimeric yellow fever 17D-Japanese encephalitis virus vaccine: doseresponse effectiveness and extended safety testing in rhesus monkeys. J Virol 74: 1742-1751.

Monath TP, Soike K, Levenbook I, Zhang ZX, Arroyo J, Delagrave S, Myers G, Barrett ADT, Shope RE, Rattterree M, Chambers TJ, Guirakhoo F 1999. Recombinant, chimeric live, attenuated vaccine (Chimerivax) incorporating the envelope genes of Japanese encephalitis (SA14-14-2) virus and the capsid and nonstructural genes of yellow fever (17D) virus is safe, immunogenic and protective in nonhuman primates. Vaccine 17: 1869-1882.

Muylaert IR, Chambers TJ, Galler R, Rice CM 1996. Mutagenesis of N-linked glycosylation sites of YF virus NS1: effects on RNA accumulation and mouse neurovirulence. Virology 222: 159-168.

Muylaert IR, Galler R, Rice CM 1997. Genetic analysis of Yellow Fever virus NS1 protein: identification of a temperature-sensitive mutation which blocks RNA accumulation. J Virol 71: 291-298.

Nestorowicz A, Chambers TJ, Rice CM 1994. Mutagenesis of the yellow fever virus NS2A/2B cleavage site: effects on proteolytic processing, viral replication and evidence for alternative processing of the NS2A protein. Virology 199: 114-123.

O'Reilly EK, Kao CC 1998. Analysis of RNA-dependent RNA polymerase structure and function as guided by known polymerase structures and computer predictions of secondary structure. Virology 252: 287-303.

Pletnev AG, Men R 1998. Attenuation of Langat virus tick-borne flavivirus by chimerization with mosquito-borne flavivirus dengue type 4. Proc Natl Acad Sci USA 95: 1746-1751.

Pletnev AG, Bray M, Huggins J, Lai CJ 1992. Construction and characterization of chimeric tick-borne encephalitis/dengue type 4 viruses. Proc Natl Acad Sci USA 89: 10532-10536.

Pletnev AG, Bray M, Lai CJ 1993. Chimeric tick-borne encephalitis and dengue type 4 viruses: effects of mutations on neurovirulence for mice. $J$ Virol 67: 4956-4963.

Pryor MJ, Gualano RC, Lin B, Davidson AD, Wright PJ 1998. Growth restriction of dengue virus type 2 by site-specific mutagenesis of virus-encoded glycoproteins. J Gen Virol 79: 2631-2639.

Pur B, Polo S, Hayes CG, Falgout B 2000. Construction 
of a full length infectious clone for dengue-1 virus Western Pacific 74 strain. Virus Genes 20: 57-63.

Racaniello VR, Baltimore D 1981. Cloned poliovirus complementary DNA is infectious in mammalian cells. Science 214: 916-919.

Rice CM 1996. Flaviviridae: the viruses and their replication. In BN Fields, DM Knipe, PM Howley (eds), Fields Virology, 3rd ed., Raven Press, USA, p. 931960.

Rice CM, Grakoui A, Galler R, Chambers TJ 1989. Transcription of infectious yellow fever virus RNA from full-length cDNA templates produced by in vitro ligation. The New Biol 1: 285-296.

Rice CM, Lenches E, Eddy SR, Shin SJ, Sheets RL, Strauss JH 1985. Nucleotide sequence of yellow fever virus: implications for flavivirus gene expression and evolution. Science 229: 726-733.

Rose CSP, Evans DJ 1990 Poliovirus antigen chimeras. Trends Biotechnol 9: 415-421.

Smith HH, Penna HA, Paoliello A 1938. Yellow fever vaccination with cultured virus (17D) without immune serum. Am J Trop Med 18: 437-468.

Steffens S, Thiel HJ, Behrens SE 1999. The RNA-dependent RNA polymerases of different members of the family Flaviviridae exhibit similar properties in vitro. J Gen Virol 80: 2583-2590.

Stocks CE, Lobigs M 1998. Signal peptidase cleavage at the flavivirus C-prM junction: dependenceon the viral NS2B-3 protease for efficient processing requires determinants in $\mathrm{C}$, the signal peptide and prM. J Virol 72: 2141-2149.
Stokes A, Bauer JH, Hudson P 1928. Experimental transmission of yellow fever to laboratory animals. Am J Trop Med Hyg 8: 103-164.

Sumiyoshi H, Hoke CH, Trent DW 1992 Infectious Japanese encephalitis virus RNA can be synthesized from invitro-ligated cDNA templates. J Virol 66: 54255431.

Theiler M, Smith HH 1937a. The effect of prolonged cultivation in vitro upon the pathogenicity of yellow fever virus. J Exp Med 65:767-786.

Theiler M, Smith HH 1937b. The use of yellow fever virus modified by in vitro cultivation for human immunization. J Exp Med 65: 787-800.

Wengler G, Wengler G 1993. The NS 3 nonstructural protein of flaviviruses contains an RNA triphosphatase activity. Virology 197: 265-273.

Wengler G, Castle E, Leidner U, Nowak T, Wengler G 1985 Sequence analysis of the membrane protein V3 of the flavivirus West Nile virus and of its gene. Virology 147: 264-274.

WHO 1993. The immunological basis for immunization 8: yellow fever. World Health Organization, Geneva.

Yamshichikov VF, Compans RW 1995. Formation of the flavivirus envelope: role of the viral NS2B-NS3 protease. J Virol 69: 1995-2003.

Yamshichikov VF, Trent DW, Compans RW 1997. Upregulation of signalase processing and induction of prM-E secretion by the flavivirus NS2B-NS3 protease: roles of protease components. J Virol 71: 43644371. 